\title{
Self-Disclosure in Social Networking Sites in Saudi Arabia
}

\author{
Basmah Emad ALQadheeb ${ }^{1} \&$ Othman Ibraheem Alsalloum $^{1}$ \\ ${ }^{1}$ Department of Management Information Systems, College of Business Administration, King Saud University, \\ Riyadh, Saudi Arabia \\ Correspondence: Basmah Emad ALQadheeb, Department of Management Information Systems, College of \\ Business Administration, King Saud University, Riyadh, Saudi Arabia. E-mail: balqadheelb@ksu.edu.sa
}

Received: December 24, 2017

Accepted: August 6, 2018

Online Published: September 6, 2018

doi:10.5539/ijbm.v13n10p96

URL: https://doi.org/10.5539/ijbm.v13n10p96

\begin{abstract}
Millions of people worldwide visit social network sites (SNSs) daily, such as Facebook, Twitter, and Snapchat. We examined a model based on the privacy calculus theory to better understand and determine what motivates users to disclose personal information on SNSs in Saudi Arabia. A total of 550 respondents participated in an online survey. The analysis results indicate that Saudi SNS users are primarily motivated by the convenience of maintaining and developing new relationships, self-presentation, and platform enjoyment. The results also indicate that privacy risks are a critical barrier to information disclosure. However, users become less concerned about privacy risks - and are thus more likely to disclose personal information - if they trust other SNS members and the service provider. Trust in the service provider increases if privacy control options are provided. In addition, the results show that gender influences the motivations to self-disclose personal information. Based on the analysis results, recommendations for service providers are provided.
\end{abstract}

Keywords: social media, social networking sites, SNSs, self-disclosure, information disclosure, privacy, Saudi Arabia

\section{Introduction}

In the past few years, the use of Web 2.0 technology, specifically social media platforms, has grown tremendously and has changed the ways in which people interact and communicate. Social networking sites (SNSs) are a subset of social media platforms that allow users to create profiles that include personal information. On SNSs, users can share text and photos, and interact with other members easily (Ellison, 2007). Recently, particularly during the last decade, participation on SNSs has become a daily activity for most people worldwide. Studies show that $94 \%$ of Internet users have at least one social media account and that $98 \%$ of those users visited or used a social network in June 2017 (GlobalWebIndex, 2017).

Social media penetration is high in Saudi Arabia. Table 1 shows the engagement levels of digital consumers in Saudi Arabia for various forms of media. Compared to broadcast radio, print press, online press, and game consoles, social networking had the most heavy users, and only a low percentage were classified as non-users (GlobalWebIndex, 2017).

Table 1. Media consumption segmentation-Engagement levels for different media

\begin{tabular}{|c|c|c|c|c|c|}
\hline & Non-Users & Light & Medium & High & Heavy Users \\
\hline Broadcast Radio & $41.3 \%$ & $33.7 \%$ & $10.8 \%$ & $10.9 \%$ & $3.4 \%$ \\
\hline Physical Press & $42.8 \%$ & $31.9 \%$ & $9.6 \%$ & $11.6 \%$ & $4.0 \%$ \\
\hline Online Press & $27.6 \%$ & $28.4 \%$ & $17.8 \%$ & $13.8 \%$ & $12.4 \%$ \\
\hline Social Networks / Services & $13.1 \%$ & $11.5 \%$ & $13.8 \%$ & $16.0 \%$ & $45.7 \%$ \\
\hline Games Consoles & $41.2 \%$ & $21.8 \%$ & $11.3 \%$ & $12.6 \%$ & $13.0 \%$ \\
\hline
\end{tabular}


According to Global Web Index (2017), Saudi citizens spend an average of two hours and 56 minutes on social media each day, compared to the global average of two hours and six minutes. Global Web Index (2017) also shows that the average number of social media accounts per person in Saudi Arabia is 10.7, compared to the global average of 7.8 accounts. Figure 1 compares Saudi and global users of prominent global social/messaging services.

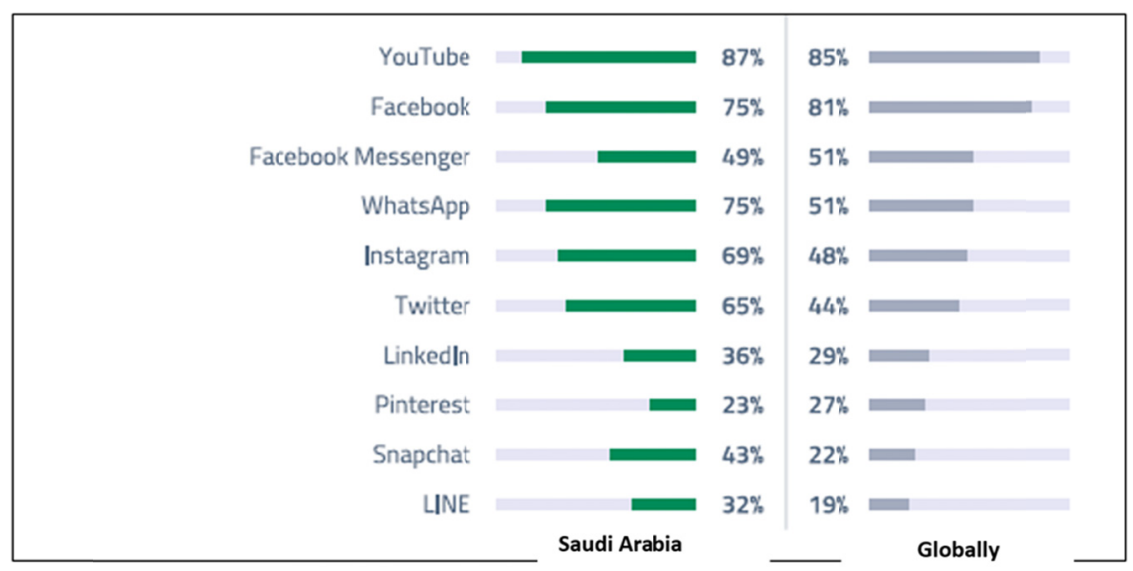

Figure 1. Top global social/messaging services. \% of visits/use of SNSs, Saudi Arabia and globally

Source: Global Web Index, 2017.

When individuals create a social networking account, they are expected to share some personal information, photographs, and preferences that reflect their real identities. For many individualls, disclosing personal information exposes them to privacy risks. However, a primary function of an SNS is sharing information; thus, self-disclosure is important.

A previous study into self-disclosure in SNSs applied the privacy calculus theory to explain why users are willing to disclose personal information (Krasnova et al., 2010). That study focused on how perceived costs and benefits affect self-disclosure in SNSs. According to Wang et al. (2016), gender differences are important, and they showed that women self-disclose more than men. Other studies have shown that men and women have different motivations regarding self-disclosure (Li-Barber, 2012; Malik et al., 2016; Sheldon, 2013; Tifferet \& Vilnai-Yavetz, 2014). Therefore, this study investigates gender differences relative to self-disclosure on SNS among Saudi citizens.

In Saudi Arabia, privacy concerns go beyond management of personal boundaries. Self-disclosure in SNSs is primarily related to the optimization and management of cultural expectations and is strongly influenced by Islamic considerations (Abokhodair \& Vieweg, 2016) .Therefore, Saudi people may be particularly concerned about privacy and may be less likely to disclose personal information. In addition, the motivation of Saudi SNS's users to disclose information may differ from users from other cultures. Therefore, investigating whether Saudi SNSs users will disclose personal information to obtain perceived benefits regardless of their concerns about privacy risks is important.

Privacy is a concern for both men and women in the Arab region. Abokhodair and Vieweg (2016) discussed privacy in SNSs in terms of protecting awrah and maintaining hurma. That study showed that, in Arab Gulf countries, cultural concepts, particularly those related to gender, play a significant role in SNS usage. Their findings showed that cultural sensitivity significantly influenced user behavior on SNSs. Thus, gender differences may be more pronounced in Saudi Arabia.

This research will answer the following questions: What is the impact of the perceived costs and benefits of self-disclosure on SNSs in Saudi Arabia? Do gender differences play a role in SNS self-disclosure in Saudi Arabia? To the best of our knowledge, no study has addressed SNS self-disclosure in Saudi Arabia; thus, this paper will contribute to the literature by examining the impacts of perceived costs and benefits and gender differences for SNS users in Saudi Arabia related to disclosing personal information.

The remainder of this paper is organized as follows. A literature review is presented in Section 2. A theoretical 
model and hypotheses are presented in Section 3. The research methodology is described in Section 4, and a data analysis is presented in Section 5. Conclusions and potential implications are presented in Section 6, and limitations and future work are given in Section 7.

\section{Literature Review}

\subsection{Self-Disclosure and Online Self-Disclosure}

Self-disclosure has been a focus of social science studies since the 1960s. According to Jourard $(1964,1971)$, self-disclosure can be viewed as making oneself manifest such that other people can perceive that self. Altman and Taylor (1973) proposed that self-disclosure plays a critical role in the process through which people move from being acquaintances to forming a close relationship. Cozby (1973) reviewed self-disclosure in a variety of contexts, specifically self-disclosure as a personality attribute, in interpersonal relationships, and in therapist-client relationships. He conceptualized self-disclosure as any information relating to oneself that is communicated verbally by an individual to another individual. Derlega et al. (1993) expanded the definition of self-disclosure to include any verbally revealed personal information, such as thoughts, feelings, and experiences.

Self-disclosure can be measured based on three parameters. According to Cozby (1973), the breadth or volume of information disclosed, the intimacy (depth) of the information disclosed, and the amount of time spent disclosing personal information are vital elements that can be used to identify and measure self-disclosure. Revealing personal information is related to the well-being and maintenance of relationships, intimacy creation, psychotherapeutic processes, and therapeutic alliances. Accordingly, the self-disclosure domain originated from verbal communication research. This domain has attracted increasing attention, particularly in the last two decades, and is becoming a mainstream subject in various areas, such as computer-mediated communication and the formation and maintenance of relationships, trust, and privacy management in online environments due to changes in information and communication technologies.

Self-disclosure plays a role in various online environments. For example, maintaining good relationships is essential in business environments (Chou et al., 2009; Kang et al., 2012). Kang et al. (2012) identified several factors that play a significant role in building relationships between clients and online shopping malls. First, the responsiveness and trustworthiness of website-based shopping malls are positively correlated with self-disclosure; second, social presence and the effectiveness of the Internet as communication tools influence the likelihood of self-disclosure (Kang et al., 2012). Importantly, the ease of Internet use and online privacy assurance statements do not significantly influence the amount of information disclosed by customers. However, the amount of information disclosed by companies is related to consumer trust and willingness to self-disclose when first visiting a company's website (Chou et al., 2009).

More recent research has begun to look more closely at the roles of self-disclosure in SNSs. SNS users find online self-disclosure essential to maintaining their social networking friendships and extending relationships to other spheres. In the next section, specific characteristics of SNSs and literature related to the role of self-disclosure on SNSs will be reviewed.

\subsection{Self-Disclosure in SNSs}

Social media can be viewed as Internet-based channels that individuals use to opportunistically and selectively present themselves in real time or asynchronously (Carr \& Hayes, 2015). Users present themselves to both broad and narrow audiences, which obtain some form of value from the content generated by the users and the perceived interaction with others. Social media platforms have a variety of forms, such as blogs, forums, social news sites, media sharing sites, microblogging sites, bookmarking sites, SNSs, and social messaging applications.

The increasing popularity of social media platforms has led to an increasing need for self-disclosure online. In such platforms, self-disclosure may occur in various ways. For example, it can involve posting a picture, posting personal information, providing status updates, or revealing personal preferences and experiences when engaging in public communication with other members of an online community (Cheung et al., 2015). When participating in SNSs, individuals tend to reveal information and expose critical personal data. Online platforms encourage people to disclose information because doing so can have positive benefits, such as the creation and maintenance of online relationships. In addition, disclosing personal information sometimes has entertainment value (Cheung et al., 2015). Moreover, social media platforms can create the impression that a person's well-being matters and that other people care about their personal issues, which can contribute to better mental health. Huang (2016) found that self-disclosure significantly influenced social support and online social 
well-being. However, there are inherent risks associated with revealing private information, such as identity theft, being targeted by cyber-criminals, harassment, cyber bullying, and theft of intellectual property (Haynes \& Robinson, 2015).

Previous studies have focused on the relationship between privacy issues and information disclosure in SNSs. In a study about why people share private information on SNSs, Lee et al. (2013) pointed out the contradiction between online attitudes and online behaviors. They argued that social media users consider the tradeoff between the risk of disclosure and the benefits of information sharing; thus, users may actively reveal personal information even though they are concerned about the potential risks (Lee et al., 2013). Barnes (2006) refers to this as the privacy paradox. Another study demonstrated that privacy concerns do not influence self-disclosure significantly (Taddicken, 2014). Taddicken (2014) found that user perception of the relevance of the site and the number of applications used were more influential factors. However, other studies found that privacy concerns directly affect personal information disclosure. For example, Nemec Zlatolas et al. (2015) found a significant correlation between privacy concerns and self-disclosure. Yet, while these studies focused on risks that limit information disclosure in SNSs, they did not examine factors that motivate users to participate in SNSs and disclose personal information.

Other studies have focused on the relationships among personality traits and the tendency to disclose personal information. Varnali and Toker (2015) found that self-disclosure on SNSs mediates the impact of communication-based personality characteristics. Moreover, they found significant independent effects relative to the subjective norm and SNS affinity (Varnali \& Toker, 2015). This implies that communication-based personality characteristics can influence decisions about whether to post personal information. On the other hand, Chen et al. (2016) found that the centrality of personality characteristics is positively correlated with the degree of self-disclosure. For example, extroverts were found to provide more accurate information when holding the cognition dimension (i.e., shared vision) and structural dimension (i.e., centrality) constant. However, the method used to measure extroversion may not be reliable because it involves a subjective evaluation. In addition, disclosures may be influenced by other aspects, such as culture and social norms.

Several studies have explored how culture is related to information disclosure on SNSs. Krasnova et al. (2012) found that trusting belief plays a significant role in self-disclosure decisions, particularly for users from individualistic cultures; in addition, avoidance of uncertainty influences privacy concerns. Therefore, their findings showed greater cultural sensitivity when investigating and influencing user behavior on SNSs. On the other hand, Liang et al. (2016) observed that, in collectivistic societies, Twitter users' privacy settings positively influenced self-disclosure; in contrast, privacy settings were not as important for users in individualistic societies. The authors also claimed that other factors, such as Internet penetration, can predict the use of privacy settings and the disclosure of location information (Liang et al., 2016). However, we argue that cultural values and self-disclosure have little or no correlation.

The few studies that have focused on the Saudi context concentrated on awareness of privacy and trust in social media. Abokhodair and Vieweg (2016) reported that, in the Arabian Gulf (Saudi Arabia and Qatar), privacy goes beyond management of personal boundaries. Thus, self-disclosure in this region is primarily related to the optimization and management of cultural expectations and focuses on an Islamic perspective. A study into Saudi women's attitudes toward privacy in relation to blackmail threats on Facebook indicated that they are concerned about privacy and know how to change their privacy settings (Al-Saggaf, 2016). However, this study only examined one social media platform; thus, the findings may not be applicable to other platforms. In addition, the study had a relatively narrow focus on blackmail threats.

Generally, Saudi Arabians have a low level of trust in social networks. A majority of people (59\%) in Saudi Arabia indicated that they would not reveal their true identities. On the other hand, Saudi social media users do not appear to feel any particular threat associated with SNSs (Dimitrios \& Violettas, 2014). However, these studies focused on levels of awareness and did not consider what motivates Saudi users to disclose personal information on SNSs.

\subsection{Privacy Calculus: Cost-Benefit Framework}

The privacy calculus model argues that a person's willingness to disclose personal information is contingent on an evaluation of the inherent risks and benefits. These can be assessed relative to the potential future outcomes. Individuals are more likely to disclose personal information if they believe they will be able to manage the potential consequences, and individuals may refrain from disclosing such information if they are concerned about the fate of their information in the future. For example, people may consider how future technological developments will affect the ongoing privacy of information they previously disclosed (Laufer \& Wolfe, 1997). 
The privacy calculus model can also be applied to consumer transactions. Here, the cost-benefit analysis considers an organization's perceived integrity. If organizations provide privacy policies that clearly indicate how information will be used, then consumers will be more likely to disclose personal information, even for marketing purposes (Culnan \& Armstrong, 1999). Based on an extended privacy calculus model for e-commerce transactions, Dinev and Hart (2006) found that perceived risks influence customers' willingness to purchase. However, Internet trust and personal Internet interest were important factors that can outweigh the perceived risks (Dinev \& Hart, 2006).

Regarding the application of the privacy calculus to SNSs, various empirical studies (Dienlin \& Metzger, 2016; Krasnova et al., 2010; Min \& Kim, 2015, Trepte et al., 2017; Zhang et al., 2015) have applied the theoretical reasoning from Dinev and Hart (2006) and Culnan and Armstrong (1999). Krasnova et al. (2010) used data from 259 respondents in German to test their theoretical privacy calculus model (note that more than $85 \%$ of the respondents were students). Their results indicated that the perceived benefits and risks influenced online self-disclosure significantly (Krasnova et al., 2010). In addition, the results demonstrated that maintaining relationships was the primary reason why people revealed personal information on SNSs, followed by platform enjoyment (Krasnova et al., 2010). Furthermore, the perceived privacy risk negatively impacted individual willingness to reveal personal information (Krasnova et al., 2010). However, the perception of risk can be mitigated by trust in the service provider and the availability of control options (Krasnova et al., 2010).

Based on our literature review, we consider that the model proposed by Krasnova et al. (2010) provides a strong theoretical basis for investigating self-disclosure on SNSs in the Saudi context. Abokhodair and Vieweg (2016) studied privacy and social media in the Gulf region and showed that the management of personal boundaries extends to Islamic teachings, reputation maintenance, and the careful navigation of social media activity to preserve respect and modesty. However, most research into self-disclosure has been conducted in Europe, and, to date, a systematic model that highlights factors that affect information disclosure on SNSs within the Saudi context has not been reported. Therefore, this study will contribute to the literature by examining the impacts of the perceived costs and benefits as well as gender differences for SNS users in Saudi Arabia in relation to the disclosure of personal information.

\section{Theoretical Model and Hypotheses Development}

In this study, the research model built on the model of self-disclosure in social networking sites (Krasnova et al., 2010) and examine how the perceived costs and benefits affect online self-disclosure in SNSs. In addition, we also consider the role gender plays in self-disclosure. The research model is depicted in Figure 2 were adopted as the basis of this study.

\subsection{Convenience of Maintaining Existing Relationships}

A major benefit of social media is the ease with which existing relationships with other individuals can be maintained (Min \& Kim, 2015). This has become increasingly important because people tend to become geographically dispersed as they pursue educational and career opportunities. SNSs offer a valuable platform with which to ensure continued communication between people. Therefore, individuals self-disclose personal details to ensure that their friends and acquaintances remain up-to-date on the main events in their lives.

However, as stated previously, privacy risks hinder self-disclosure. In the Saudi context, where there are considerable cultural expectations and constraints, it is important to investigate whether the benefits of self-disclosure offset the risks. Here, the question becomes whether Saudis can use social media successfully to share, communicate, and keep in touch and, at the same time, maintain family honor?

The technology that supports social media platforms facilitates a wide scope of online interactions, such as sharing photographs, videos, messages, and thoughts, all of which facilitate the maintenance of relationships beyond offline or face-to-face interactions. For example, on Facebook, people can interact through status updates, wall updates, and private messages. Such activities can involve self-disclosure to maintain existing relationships and for identification, social validation, self-expression, and information sharing (Bazarova \& Choi, 2014). Similarly, Zhang et al. (2015) found it important for users to reveal themselves on Weibo, a Chinese social media platform, to take full advantage of that platform as a relationship building and maintenance tool. In addition, Cheung et al. (2015) and Krasnova et al. (2010) demonstrated empirically that the convenience of maintaining existing relationships has strong and significant positive effects on self-disclosure in SNSs. Therefore, we propose the following hypothesis:

H1a. Users' beliefs regarding the convenience of maintaining existing relationships will be positively related to their self-disclosure in SNSs. 


\subsection{Building New Relationships}

Social media facilitates meeting new people and building new relationships. In this case, self-disclosure is an easy and desirable way to create a perception of trustworthiness. Individuals are motivated to ensure that their actions are socially acceptable and justified, particularly in situations where their behavior cannot be measured. Thus, by accepting conventional social networking behaviors, individuals seek to benefit by gaining and maintaining relationships. Min and Kim (2015) found a positive relationship between the intention to disclose and the desire to manage relationships on SNSs.

As in other countries, in Saudi Arabia, online networking creates opportunities to make new connections. However, making new relationship via online networking is sometimes considered socially unacceptable in Saudi Arabia, and such activities will be frowned upon. It is therefore important to investigate whether using SNSs to make new connections motivates Saudi users.

Despite the risks associated with information disclosure on SNSs, users still reveal information to build networks and strengthen relationships (Zhang et al., 2015). Zhang et al. (2015) reported that individuals felt it was necessary to self-disclose to enjoy the benefits of social media. In the Chinese context, these benefits may include rapport creation, reputation strengthening, and attracting followers to build and maintain relationships. The importance of building new relationships and the benefits derived from participation in online social networks (OSNs) and self-disclosure have been supported empirically (Cheung et al., 2015; Krasnova et al., 2010). Therefore, we propose the following hypothesis.

H1b. Users' beliefs regarding opportunities to build new relationships will be positively related to their self-disclosure on SNSs.

\subsection{Self-Presentation on SNSS}

The role of SNSs is not limited to maintaining relationships through social interactions. Currently, social media plays many different roles, such as in the hiring process, which influences self-presentation behavior. In other words, people are willing to disclose information if they perceive a potential benefit from doing so (Dienlin \& Metzger, 2016).

SNSs offer new opportunities for impression management, such as by allowing users to create custom pages and report personal information strategically. For example, sites such as LinkedIn provide opportunities for professionals to meet, interact, and discuss shared goals relative to their careers (Paliszkiewicz \& Mądra-Sawicka, 2016). On such sites, an individual must self-disclose in the most genuine way possible to self-represent their character, qualifications, and authenticity to other members.

In the context of Saudi society, (Guta \& Karolak, 2015) found that social media sites, in the absence of the body, brought new ways of self-expression and identification among Saudi females. Therefore, it is important to investigate whether using SNSs for self- presentation motivates Saudi users to disclose more information.

SNS Users can employ multiple functionalities to manipulate their self-presentation. Min and Kim (2015) found that the perceived usefulness of a SNS relative to self-presentation positively affects the intention to self-disclose. According to Ahmed (2014), there is a significant positive correlation between the rate at which individuals use SNSs and their tendency to perceive that their online self-presentation has been successful. In addition, Cheung et al. (2015) empirically demonstrated that self-presentation has robust and significant positive effects on self-disclosure in SNSs. Therefore, we propose the following hypothesis:

\section{H1c. Users' beliefs regarding the benefits of self-presentation will be positively related to their self-disclosure in SNSs.}

\subsection{Enjoyment}

The benefits that users derive from using a SNS, such as enjoyment, and the propensity to self-disclose have been studied extensively. Syn and Oh (2015) found that people are likely to participate as well as contribute to online communities when they are entertained. According to Stern and Salb (2015), individuals are willing to self-disclose as long as they are enjoying themselves. Loiacono (2015) also agreed with the notion that benefits play a vital role in self-disclosure. Users in this study pointed to the benefits of using SNSs by terming their usage as good or fun, which in turn influences the intention to disclose their personal information.

According to Global Web Index (2017) Saudi users are motivated to use social media to fill spare time (48\%) and to find funny and entertaining content (37\%). Investigating whether these reasons to use SNSs prompt Saudi users to disclose personal information regardless of the potential risk is important.

Some social media sites, such as Facebook, provide features that can increase enjoyment, such as gaming 
applications, online purchasing, video sharing, and location reporting. It has been reported that such features motivate users to self-disclose (Hollenbaugh \& Ferris, 2014). Similarly, Cheung et al. (2015) and Krasnova et al. (2010) empirically showed that enjoyment has strong and significant positive effects on self-disclosure in social networking sites. Therefore, we propose the following hypothesis:

\section{H1d. User enjoyment will be positively related to self-disclosure on SNSs.}

\subsection{Perceived Costs of Self-Disclosure}

Privacy risk can be defined as the belief that the use of an online platform could be unsafe or result in negative consequences (Loiacono, 2015). As mentioned previously, the potential risks associated with sharing personal information on SNSs include identity theft, being targeted by cyber-criminals, online harassment, cyber bullying, and theft of intellectual property (Haynes \& Robinson, 2015).

In Saudi Arabia, the risks associated with using a SNS involve additional cultural considerations. In this region, privacy extents in SNSs goes beyond management of personal boundaries. Thus, self-disclosure is primarily related to cultural expectations and focuses on an Islamic perspective (Abokhodair \& Vieweg, 2016). Therefore, it is necessary to investigate whether such cultural constraints will hinder self-disclosure in Saudi Arabia.

The research model proposed by (Krasnova et al., 2010) was based on the privacy calculus theory (Culnan \& Armstrong, 1999), which explains the risk-benefit analysis involved in the decision to disclose personal information. In this analysis, the loss of privacy is considered the cost required to accrue benefits on SNSs. Thus, users who may be concerned about privacy may decide to disclose personal information when the potential gains surpass the expected losses (Kokolakis, 2017). In other words, perceived risk is inversely related to disclosure (Alarcón-del-Amo et al., 2014). Loiacono (2015) stated that perceived risk negatively influences the intent to use online social platforms. Moreover, an analysis of privacy antecedents relative to Facebook found a negative and significant impact on self-disclosure (Nemec Zlatolas et al., 2015). The results of these studies imply that, as people become increasingly concerned about privacy, they become less likely to disclose personal information on SNSs. Therefore, we propose the following hypothesis:

\section{H2. Perceived privacy risk will be negatively related to self-disclosure on SNSs.}

\subsection{Trust in SNS Service Providers}

The extent to which users trust an SNS service provider is an important determinant of the likelihood of users revealing personal information (Salehan et al., 2016). Such trust almost exclusively depends on beliefs about the provider's benevolence and integrity. People are more likely to self-disclose when they believe that their information is secure, i.e., protected against unauthorized access. Furthermore, if the service provider is trusted, then uncertainty or concerns related to the cost of privacy are reduced and the perceived usefulness and ease of use of an SNS increase (Alarcón-del-Amo et al., 2014).

When an SNS service provider is transparent about how individual user information is collected and shared with third parties and is perceived to be caring, honest, and consistent in its dealings with users, users will be less sensitive to the privacy risks involved in using SNSs and may increase the extent of their self-disclosure (Benson et al., 2015). Benson et al. (2015) also demonstrated that when social media users perceive that an SNS provides security notices, they will be more likely to trust the service and be more willing to share their information. In addition, Krasnova et al. (2010) empirically demonstrated that trust in an SNS service provider will be negatively related to the user's perceived risk of self-disclosure. Therefore, we propose the following hypothesis:

\section{H3a. Trust in an SNS service provider will be negatively related to the user's perceived privacy risk associated with self-disclosure.}

\subsection{Trust in SNS Members}

SNSs allow individuals to share significant amounts of personal information, such as life events, photographs, and videos. However, an individual user has limited control over other users' access to and use of such information. They must trust that other members will not abuse the personal information they have revealed. An SNS can be considered an environment in which users reciprocate by allowing access to their information (Syn \& Oh, 2015). Therefore, users must share and allow access to their personal information to enjoy the interactions facilitated by an SNS.

If an individual feel that other users are trustworthy, care about their well-being, and will not abuse their personal information, then he or she will be more likely to perceive less risk and thus to share personal information. Conversely, if other members are not willing to share their information, they will appear less trustworthy; thus, the perceived risk increases, which will lead to reduced self-disclosure. 
Therefore, the trustworthiness of the other members is a major factor that influences the perceived risk on social media networks (Salehan et al., 2016). Salehan et al. (2016) stated that social trust is viewed as a belief that people will not willingly pose harm to others. They argued that social trust positively influences individuals' attitudes toward disclosing and sharing information. In addition, higher levels of social trust reduce the perception of risk associated with sharing information. Therefore, we propose the following hypothesis:

H3b. Users' trust in SNS members will be negatively related to their perceived privacy risk of self-disclosure.

\subsection{Perceived Control over Personal Information}

Users will be more likely to self-disclose if they have control over the privacy of the information that they share. According to O'Brien and Torres (2012), SNSs such as Facebook have mechanisms, such as profile visibility and searchability, that allow individuals to control with whom they share information. Such mechanisms allow information to be accessible to the public, to friends only, or to a specific set of people.

The availability of privacy settings creates the perception that users can control their privacy (Stern \& Salb, 2015); thus, they will be likely to disclose more information. In addition, Hajli and Lin (2016) found that perceived control is negatively correlated with perceived privacy risk. Similarly, Krasnova et al. (2010) indicated that privacy settings and clear information about privacy-related procedures may significantly reduce the perception of privacy risks. Therefore, we propose the following hypothesis:

\section{H4a. Users' perceived control will be negatively related to their perceived privacy risk of disclosing} on SNSs.

Furthermore, if individuals believe that the SNS provider provides functions that allow users to control their privacy settings, they will develop a higher level of trust toward SNS providers and be more likely to self-disclose (Hajli \& Lin, 2016). Similarly, Krasnova et al. (2010) stated that trust in SNSs will increase if service providers provide privacy control mechanisms. Therefore, we propose the following hypothesis:

\section{H4b. Users' perceived control will be positively related to their trust in an SNS service provider.}

Control is regarded as an important mechanism for building confidence and trust among participating parties. In the SNS context, once users become friends, their profile and status updates will be visible to all friends in their network. A previous study demonstrated that the perceived publicness of personal information on SNSs is negatively related to the intention to self-disclose (Bateman et al., 2011). Thus, most SNSs have introduced privacy-control features that allow users to manage access to their personal information. For example, on Facebook, users can group friends and authorize access to their personal information across groups (O'Brien \& Torres, 2012). Thus, Krasnova et al. (2010) stated that perceived control, such as by limiting access to a profile, can improve trust toward other members within the community. Therefore, we propose the following hypothesis:

H4c. Users' perceived control will be positively related to their trust in other members on SNSs.

\subsection{Gender Differences in Self-Disclosure}

Beyond individual beliefs, self-disclosure is likely to be a function of personal user characteristics. Dindia and Allen (1992) focused on gender as it relates to self-disclosure and indicated that gender differences play a critical role. They found that gender influences the extent of self-disclosure, which in turn is related to the nature of the relationship or interaction and the gender of the target. Derlega et al. (1981) reported that gender plays an important role in what will be disclosed. This result conforms to typical gender stereotypes that suggest women are generally more comfortable with backstage disclosures and are more willing to share personal evaluative information, while men tend to be focused on impression management and are thus more comfortable with frontstage disclosures.

The results of earlier studies into offline self-disclosure behavior were inconclusive. A review study (Cozby, 1973) found that some studies indicated that women disclose more than men, while others concluded that there were no significant differences between men and women. Some studies into the role of gender differences in online self-disclosure on SNSs found no difference between men and women (Krasnova et al., 2012; Zhang et al., 2015). However, other studies found that women are more likely to disclose information and communicate with others on SNSs and that men and women have different motives for self-disclosure (Li-Barber, 2012; Tifferet and Vilnai-Yavetz, 2014; Sheldon, 2013; Walton and Rice, 2013; Wang et al., 2016). For example, a study that examined the main reasons why individuals use Facebook, including relationship maintenance, passing time, virtual community, coolness, and companionship, found no significant gender differences (Li-Barber, 2012). However, that study also indicated that women use Facebook more for entertainment than men do. 
In addition, the photos that men and women choose as profile pictures reflect clear gender differences. Men's photos tend to emphasize status, e.g., they wear formal clothing, while women's photos tend to emphasize family (Tifferet \& Vilnai-Yavetz, 2014). Women's profile photos also tend to be more emotionally expressive, with more smiles, direct eye contact, and fewer sunglasses (Tifferet \& Vilnai-Yavetz, 2014). This suggests that gender differences play a role in relation to self-presentation (Tifferet \& Vilnai-Yavetz, 2014).

For men and women, the number of topics discussed with recently added friends is similar; however, men's discussions tend to be more intimate, which may indicate that they are more focused on relationship building (Sheldon, 2013). With regard to privacy, women and young users are significantly more concerned about the privacy of the photos they share on Facebook (Malik et al., 2016).

Privacy is a concern for men and women in the Arab region. Sharing images that may be considered culturally inappropriate can have far-reaching consequences. If a photo is considered culturally inappropriate, it may impact the career opportunities, marriage prospects, and general well-being of an individual. However, to the best of our knowledge, no studies have considered the different motivations for self-disclosure on SNSs in Saudi Arabia or how gender affects these motivations. Thus, it is important to examine the role of gender in self-disclosure in SNSs in the Saudi context. This study examines the following hypotheses in the context of Saudi Arabia.

H5: Gender moderates the influence of the convenience of maintaining existing relationships on individual self-disclosure in SNSs.

H6: Gender moderates the influence of opportunities for building new relationships on individual self-disclosure in SNSs.

H7: Gender moderates the influence of the benefits of self-presentation on individual self-disclosure in SNSs.

H8: Gender moderates the influence of the enjoyment of platform use on individual self-disclosure in SNSs.

H9: Gender moderates the influence of perceived privacy risk on individual self-disclosure in SNSs.

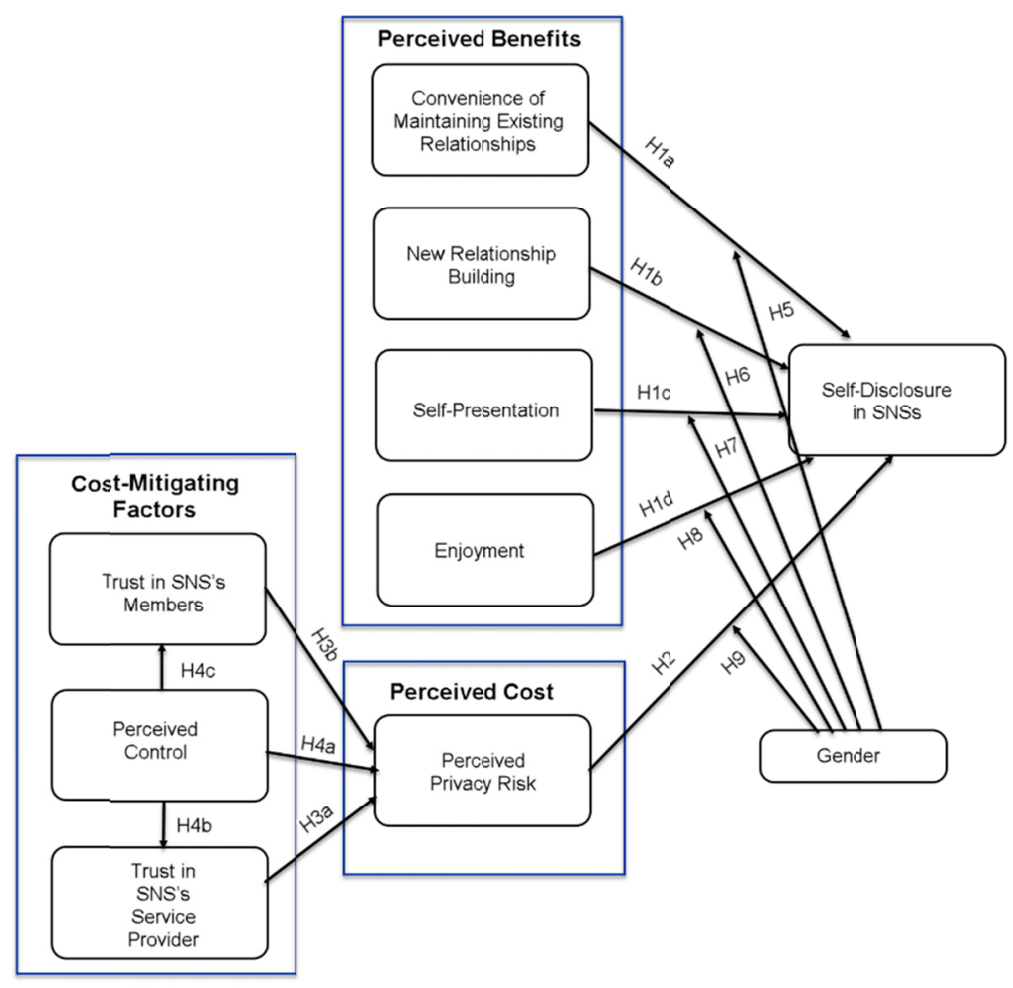

Figure 2. Research model 


\section{Research Methodology}

\subsection{Research Design}

This study adopted a quantitative approach. A web-based survey was conducted for data collection using a framework for online self-disclosure on SNSs developed by Krasnova et al. (2010) as a base to determine what motivates users to disclose personal information on SNSs in Saudi Arabia. A questionnaire was used for collecting the data for analysis. In addition, gender was included in the online self-disclosure model.

\subsection{Data Collection}

This study aims to investigate online self-disclosure on SNSs in Saudi Arabia. We developed a web-based survey instrument that we distributed through SNSs. The distribution of the questionnaire began on August 17, 2017. The sampling process was executed randomly within three weeks. To avoid biased results and to target the appropriate audience, the questionnaire was provided in Arabic. The English version of the questionnaire was translated into Arabic by two independent translators. The two versions of the questionnaires were compared to resolve any differences. The last version after modification was then used for data collection. We received 570 responses, from which 550 valid responses were obtained for subsequent analysis. The questionnaire responses were analyzed statistically using the SPSS program.

The survey included a 33-item questionnaire (27 items related to dependent and independent variables and six items related to demographic and general questions). Note that the questionnaire was adopted from previous studies, which supports our assumption that the research instrument is valid and reliable.

\subsection{Measurement and Constructs}

The following constructs were evaluated: convenience of maintaining relationships, enjoyment, relationship building, self-presentation, perceived privacy risk, perceived control, trust in SNS members, trust in SNS providers, and information disclosure. The resulting list of constructs, measurement, and their sources are presented in Table 2. Note that certain items were adjusted to fit the Saudi context. A five-point Likert scale $(1=$ strongly disagree, $2=$ disagree, $3=$ neither agree nor disagree, $4=$ agree, and $5=$ strongly agree) was used to measure all constructs.

Note that constructs can be categorized as benefits or cost. According to Krasnova et al. (2010), information disclosure is defined as the extent to which a user provides information when communicating with others (e.g., in their user profile). Also, convenience of maintaining relationships (i.e., the ease with which users can stay in touch with other SNS members) is a benefit of disclosure. Enjoyment, relationship building, and self-presentation also represent potential benefits. Here, self-presentation is defined as the value derived from being able to improve a user's self-concept relative to SNS users (Hui et al., 2006). Constructs associated with perceived cost include perceived privacy risk, which is defined as beliefs about potential negative consequences associated with information disclosure (Kim et al., 2008).

Risks can be mitigated by perceived control, which is defined as the extent to which a user is reassured by the SNS provider's privacy policies (Skinner, 1996) and privacy control options. Perceived control also involves legal assurances (i.e., beliefs that regulations, laws, or other legal structures adequately protect user privacy). According to McKnight et al. (2002), trust in SNS members and trust in SNS providers comprised beliefs that members and providers are unlikely to engage in opportunistic behavior.

\subsection{Pilot Test}

We conducted a pilot test to improve the questionnaire. A pilot test can improve data quality and minimize potential errors. Note that 30 respondents participated in the pilot test. The respondents were interviewed after completing the questionnaire to identify irregularities and provide feedback for improvement. The pilot test resulted in various changes to the questionnaire to improve the intended meaning of questions and decrease the likelihood of dropouts. 
Table 2 Constructs and measures

\begin{tabular}{|c|c|c|}
\hline Construct & Item & Item text \\
\hline $\begin{array}{l}\text { Convenience } \\
\text { of }\end{array}$ & CON1 & $\begin{array}{l}\text { 1- SNS is convenient for informing all my friends about my } \\
\text { ongoing activities }\end{array}$ \\
\hline $\begin{array}{l}\text { maintaining } \\
\text { existing }\end{array}$ & CON2 & $\begin{array}{l}\text { 2- SNS allows me to save time when I want to share something } \\
\text { new with my friends }\end{array}$ \\
\hline relationships (Chiu et al., 2006; Krasnova et al., 2010) & CON3 & $\begin{array}{l}\text { 3- I find SNS effective in strengthen my relationship with my } \\
\text { friends }\end{array}$ \\
\hline New relationship building (Krasnova et al., 2010) & RB1 & $\begin{array}{l}\text { 4- Through SNS I get connected to new people who share my } \\
\text { interests. }\end{array}$ \\
\hline & $\begin{array}{l}\text { RB2 } \\
\text { RB3 }\end{array}$ & $\begin{array}{l}\text { 5- } \quad \text { The SNS helps me to expand my network. } \\
\text { 6- } \quad \text { I get to know new people through SNS. }\end{array}$ \\
\hline Self-presentation (Walther et al., 2001) & $\begin{array}{l}\text { SP1 } \\
\text { SP2 } \\
\text { SP3 }\end{array}$ & $\begin{array}{l}\text { 7- } \quad \text { I try to make a good impression on others on SNS. } \\
\text { 8- } \quad \text { I try to present myself in a favorable way on the SNS. } \\
\text { 9- } \quad \text { The SNS helps me to present my best sides to others. }\end{array}$ \\
\hline Enjoyment (Nambisan \& Baron, 2007) & $\begin{array}{l}\text { EN1 } \\
\text { EN2 } \\
\text { EN3 }\end{array}$ & $\begin{array}{l}\text { 10- When I am bored I often login to SNS. } \\
11-\quad \text { I find SNS entertaining. } \\
12-\quad \text { I spend enjoyable and relaxing time on SNS. }\end{array}$ \\
\hline $\begin{array}{l}\text { Perceived privacy risk_partly on (Malhotra et al., 2004) } \\
\text { and self-developed }\end{array}$ & RISK1 & $\begin{array}{l}\text { 13- Overall, I find it risky to publish my personal information on } \\
\text { SNS. }\end{array}$ \\
\hline & RISK2 & $\begin{array}{l}\text { 14- I fear that something unpleasant can happen to me due to my } \\
\text { presence on the SNS. }\end{array}$ \\
\hline & RISK3 & $\begin{array}{l}\text { 15- I fear that unauthorized people can access my personal } \\
\text { information. }\end{array}$ \\
\hline $\begin{array}{l}\text { Trust in SNS service provider (Jarvenpaa et al., 1999, } \\
\text { McKnight et al., 2002) }\end{array}$ & TP1 & $\begin{array}{l}\text { 16- SNS makes good-faith efforts to address most member } \\
\text { concerns. }\end{array}$ \\
\hline & $\begin{array}{l}\text { TP2 } \\
\text { TP3 }\end{array}$ & $\begin{array}{l}\text { 17- } \text { SNS is honest in its dealings with me } \\
18-\quad \text { SNS is trustworthy. }\end{array}$ \\
\hline Trust in SNS members (Chiu et al., 2006; McKnight et al., & TM1 & 19- Other SNS members will do their best to help me \\
\hline 2002) & $\begin{array}{l}\text { TM2 } \\
\text { TM3 }\end{array}$ & $\begin{array}{l}\text { 20- Other SNS members do care about the well-being of others } \\
21-\quad \text { Other SNS members are trustworthy. }\end{array}$ \\
\hline Perceived control (Krasnova et al., 2010) & $\begin{array}{l}\text { PCL1 } \\
\text { PCL2 }\end{array}$ & $\begin{array}{l}\text { 22- I feel in control over the information I provide on SNS. } \\
\text { 23- Privacy settings allow me to have full control over the } \\
\text { information I provide on SNS. }\end{array}$ \\
\hline $\begin{array}{l}\text { Self-disclosure in social networking sites (Krasnova et al., } \\
\text { 2010) }\end{array}$ & $\begin{array}{l}\text { PCL3 } \\
\text { SD1 } \\
\text { SD2 } \\
\text { SD3 }\end{array}$ & $\begin{array}{l}\text { 24- I feel in control over who can view my information on SNS. } \\
\text { 25- I have a comprehensive profile on SNS. } \\
\text { 26- I find time to keep my profile up-to-date. } \\
\text { 27- I keep my friends updated about what is going on in my life } \\
\text { through SNS. }\end{array}$ \\
\hline
\end{tabular}

\subsection{Credibility of Research Findings}

\subsubsection{Reliability and Validity}

Reliability describes the extent to which the collected data yield consistent findings. A reliable study will return the same results when replicated by another researcher. Validity assures the credibility of research and describes the degree to which a study measures what it intends to measure. To determine reliability, this study used Cronbach's alpha (denoted $\alpha$ ) to measure internal consistency (i.e., how closely items in a set are related). Generally, a questionnaire with an $\alpha$ value of 0.7 is considered reliable. 
Table 3. Reliability measures using Cronbach's alpha coefficient (SPSS)

\begin{tabular}{lll}
\hline Dimension & Items & Cronbach's alpha coefficients \\
\hline Convenience of maintaining existing relationship & 3 & 0.788 \\
New relationship building & 3 & 0.848 \\
Self-presentation & 3 & 0.782 \\
Enjoyment & 3 & 0.779 \\
Perceived privacy risk & 3 & 0.768 \\
Trust in SNS service provider & 3 & 0.812 \\
Trust in SNS members & 3 & 0.767 \\
Perceived control & 3 & 0.826 \\
Self-disclosure & 3 & 0.765 \\
Total & 27 & 0.836 \\
\hline
\end{tabular}

As shown in Table 3, the overall reliability coefficient is 0.836 , which means that the questionnaire was reliable. Here, validity was defined by calculating the square root of the reliability result $(91 \%)$, which indicates that the study adequately measures what it intends to measure.

\subsubsection{Sampling Adequacy Testing}

Adequate sampling requires a statistical sample size that is sufficiently large to provide satisfactory test results with adequate precision while minimizing the effect of chance. This study used the Kaiser-Meyer-Olkin (KMO) test to determine whether the collected data were suitable for factor analysis. The KMO test measures sampling adequacy for a complete model and for each variable in the model. The test measures the proportion of variance among variables that might be common variance. KMO values less than 0.6 indicate that sampling is inadequate and remedial action is required, and KMO values between 0.8 and 1 indicate that the sampling is adequate. The KMO value was 0.8 , which indicates a sufficient sample size.

\section{Data Analysis}

\subsection{Demographics and General Characteristics of Respondents}

Descriptive statistics were used to analyze the demographic variables. In total, 550 responses were received and accepted as valid. A demographic profile of the respondents is presented in Table 4. Among the 550 respondents, $42.0 \%$ were females and $58.0 \%$ were males, and $4.5 \%$ were 18 years old or younger. Most respondents $(51.1 \%)$ were $19-29$ years old, $28.0 \%$ were $30-39,9.5 \%$ were $40-49,5.6 \%$ were 50 to 59 , and a few respondents were 60 years or older. The education demographics show that $63.5 \%$ of the participants had achieved a bachelor's degree, $12.9 \%$ had a master's degree, $1.8 \%$ had achieved a $\mathrm{PhD}, 8.4 \%$ had a diploma, and $13.5 \%$ had a low level of education.

Most respondents were SNS users (99.6\%); the remaining $0.4 \%$ were not members of SNSs. The $0.4 \%$ who were not SNS users had tried an SNS once and found it uninteresting. 
Table 4. Demographics and general profile

\begin{tabular}{|c|c|c|c|}
\hline Variables & Answers & Frequencies & Percentages \\
\hline \multirow{3}{*}{ Gender } & Male & 319 & $58.0 \%$ \\
\hline & Female & 231 & $42.0 \%$ \\
\hline & Total & 550 & $100.0 \%$ \\
\hline \multirow{7}{*}{ Age } & 18 or less & 25 & $4.5 \%$ \\
\hline & 19 to 29 & 281 & $51.1 \%$ \\
\hline & 30 to 39 & 154 & $28.0 \%$ \\
\hline & 40 to 49 & 52 & $9.5 \%$ \\
\hline & 50 to 59 & 31 & $5.6 \%$ \\
\hline & 60 or more & 7 & $1.3 \%$ \\
\hline & Total & 550 & $100.0 \%$ \\
\hline \multirow{6}{*}{ Educational level } & High school or less & 74 & $13.5 \%$ \\
\hline & Diploma & 46 & $8.4 \%$ \\
\hline & Bachelor's degree & 349 & $63.5 \%$ \\
\hline & Master's degree & 71 & $12.9 \%$ \\
\hline & $\mathrm{PhD}$ & 10 & $1.8 \%$ \\
\hline & Total & 550 & $100.0 \%$ \\
\hline \multirow{3}{*}{$\begin{array}{l}\text { Are you a member of social } \\
\text { network sites SNS? }\end{array}$} & Yes & 548 & $99.6 \%$ \\
\hline & No & 2 & $.4 \%$ \\
\hline & Total & 550 & $100.0 \%$ \\
\hline \multirow{5}{*}{$\begin{array}{l}\text { If no, please tick the reason, } \\
\text { why you do not use SNS }\end{array}$} & $\begin{array}{l}\text { I don't know what a social } \\
\text { network is }\end{array}$ & 0 & $0 \%$ \\
\hline & I am not interested in joining SNS & 0 & $0 \%$ \\
\hline & $\begin{array}{l}\text { I tried once but it was not } \\
\text { interesting }\end{array}$ & 2 & $100 \%$ \\
\hline & No privacy & 0 & $0 \%$ \\
\hline & Total & 2 & $100 \%$ \\
\hline
\end{tabular}

\subsection{Hypotheses Testing}

The hypotheses proposed by this study were tested by applying chi-square and Spearman correlation techniques. The null hypotheses were developed from alternative hypotheses in order to test the alternative hypotheses.

The relationship between the perceived benefits dimension and perceived privacy risk dimension with self-disclosure was analyzed.

Table 5 Chi-square test for self-disclosure

\begin{tabular}{|c|c|c|c|c|c|c|c|}
\hline \multicolumn{8}{|c|}{ Self-disclosure } \\
\hline No & Dimension & $\begin{array}{l}\text { P-Value for } \\
\text { Chi square }\end{array}$ & $\begin{array}{l}\text { Strength of the } \\
\text { relationship }\end{array}$ & Ranking & $\begin{array}{l}\text { Spearman } \\
\text { Correlation }\end{array}$ & $\begin{array}{l}\text { P-Value for } \\
\text { Spearman }\end{array}$ & Note \\
\hline 1 & $\begin{array}{l}\text { Convenience of maintaining } \\
\text { existing relationship }\end{array}$ & 0.000 & 0.419 & 1 & 0.398 & 0.000 & $\begin{array}{l}\text { Positive } \\
\text { relationship }\end{array}$ \\
\hline 2 & New relationship building & 0.000 & 0.347 & 2 & 0.275 & 0.000 & $\begin{array}{l}\text { Positive } \\
\text { relationship }\end{array}$ \\
\hline 3 & Self-presentation & 0.000 & 0.315 & 4 & 0.245 & 0.000 & $\begin{array}{l}\text { Positive } \\
\text { relationship }\end{array}$ \\
\hline 4 & Enjoyment & 0.000 & 0.345 & 3 & 0.229 & 0.000 & $\begin{array}{l}\text { Positive } \\
\text { relationship }\end{array}$ \\
\hline 5 & Perceived privacy risk & 0.000 & 0.233 & 5 & -0.161 & 0.000 & $\begin{array}{l}\text { Negative } \\
\text { relationship }\end{array}$ \\
\hline
\end{tabular}

Table 5 shows the relationships among the perceived benefits dimension and perceived privacy risk dimension with self-disclosure. Here, since significance is 0 or less than 0.05 , we reject the null hypotheses and accept all 
alternative hypotheses. While the direction of the impact is positive among the perceived benefits dimension (convenience of maintaining existing relationship, new relationship building, self-presentation, and enjoyment), the direction of the impact is negative in the perceived privacy risk dimension. However, the strength of the relationship differs among the dimensions, and the results show that the impact of perceived privacy risk on self-disclosure is 0.233 , which is less than that of the perceived benefits.

The relationship between the cost mitigating factors and perceived privacy risk was also analyzed.

Table 6. Chi-square test for prceived risk

\begin{tabular}{|c|c|c|c|c|c|c|c|}
\hline \multicolumn{8}{|c|}{ Perceived Privacy Risk } \\
\hline No & Dimension & $\begin{array}{ll}\text { P-Value for } \\
\text { Chi square }\end{array}$ & $\begin{array}{l}\text { Strength of the } \\
\text { relationship }\end{array}$ & Ranking & $\begin{array}{l}\text { Spearman } \\
\text { Correlation }\end{array}$ & $\begin{array}{l}\text { P-Value for } \\
\text { Spearman }\end{array}$ & Note \\
\hline 1 & $\begin{array}{l}\text { Trust in SNS } \\
\text { service provider }\end{array}$ & 0.029 & 0.221 & 2 & -0.185 & 0.001 & $\begin{array}{l}\text { Negative } \\
\text { relationship }\end{array}$ \\
\hline 2 & $\begin{array}{l}\text { Trust in SNS } \\
\text { members }\end{array}$ & 0.002 & 0.254 & 1 & -0.017 & 0.007 & $\begin{array}{l}\text { Negative } \\
\text { relationship }\end{array}$ \\
\hline 3 & Perceived control & 0.035 & 0.207 & 3 & -0.125 & 0.003 & $\begin{array}{l}\text { Negative } \\
\text { relationship }\end{array}$ \\
\hline
\end{tabular}

Table 6 shows the relationships among the cost mitigating factors and perceived privacy risk. Here, since significance is 0 or less than 0.05 , we reject the null hypotheses and accept all alternative hypotheses. The direction of the impact is negative among the cost mitigating factors (trust in SNS service provider, trust in SNS members, and perceived control). However, the strength of the relationship differs among the dimensions, and the results show that the impact of perceived control on perceived privacy risk is 0.207 , which is less than that of the other factors.

The relationship between the two dimensions (trust in SNS service provider and trust in SNS members) and perceived control was also analyzed.

Table 7. Chi-square test for preceived control

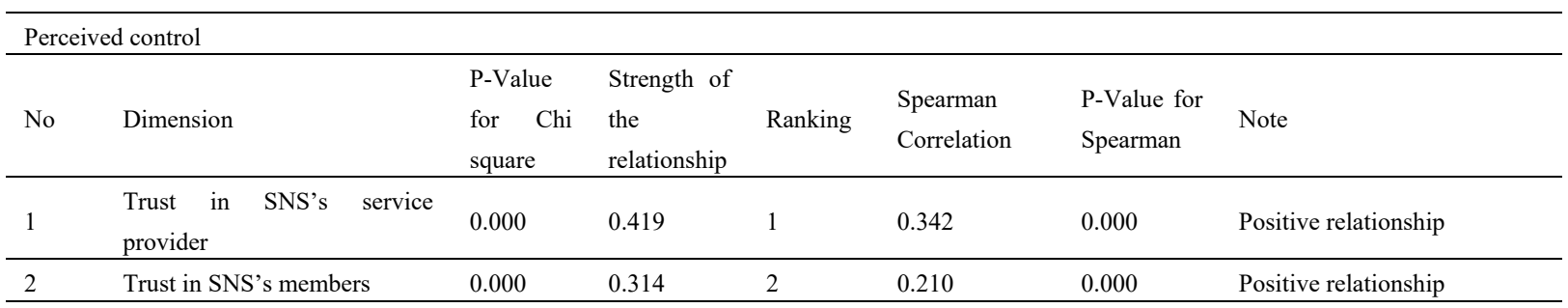

Table 7 shows the relationships of the two dimensions (trust in SNS service provider and trust in SNS members) and perceived control. Here, since significance is 0 or less than 0.05 , we reject the null hypotheses and accept all alternative hypotheses. The direction of the impact is positive and the strength of the relationship differs between dimensions. The results show that the impact of trust in SNS service provider on perceived control is 0.419 , which is greater than that of trust in SNS members

Moreover, the results of independent samples using the Chi square test were analyzed to recognize significant differences between the responses toward different motivations according to gender. 
Table 8. Chi-square test for self-disclosure (male)

\begin{tabular}{|c|c|c|c|c|c|c|c|}
\hline \multicolumn{8}{|c|}{ Self-disclosure (males) } \\
\hline No & Dimension & $\begin{array}{l}\text { P-Value } \\
\text { for Chi } \\
\text { square }\end{array}$ & $\begin{array}{l}\text { Strength of } \\
\text { the } \\
\text { relationship }\end{array}$ & Ranking & $\begin{array}{l}\text { Spearman } \\
\text { Correlation }\end{array}$ & $\begin{array}{l}\text { P-Value for } \\
\text { Spearman }\end{array}$ & Note \\
\hline 1 & $\begin{array}{l}\text { Convenience of Maintaining } \\
\text { existing relationship }\end{array}$ & 0.000 & 0.383 & 2 & 0.344 & 0.000 & Positive relationship \\
\hline 2 & New relationship building & 0.000 & 0.389 & 1 & 0.281 & 0.000 & Positive relationship \\
\hline 3 & Self-presentation & 0.000 & 0.345 & 4 & 0.286 & 0.000 & Positive relationship \\
\hline 4 & Enjoyment & 0.000 & 0.351 & 3 & 0.250 & 0.000 & Positive relationship \\
\hline 5 & Perceived privacy risk & 0.009 & 0.303 & 5 & -0.182 & 0.001 & Negative relationship \\
\hline
\end{tabular}

Table 9. Chi-square tes for self-disclosure (female)

\begin{tabular}{|c|c|c|c|c|c|c|c|}
\hline \multicolumn{8}{|c|}{ Self-disclosure (female) } \\
\hline No & Dimension & $\begin{array}{l}\text { P-Value } \\
\text { for Chi } \\
\text { square }\end{array}$ & $\begin{array}{l}\text { Strength of } \\
\text { the } \\
\text { relationship }\end{array}$ & Ranking & $\begin{array}{l}\text { Spearman } \\
\text { Correlation }\end{array}$ & $\begin{array}{l}\text { P-Value for } \\
\text { Spearman }\end{array}$ & Note \\
\hline 1 & $\begin{array}{l}\text { Convenience of maintaining } \\
\text { existing relationship }\end{array}$ & 0.000 & 0.477 & 1 & 0.473 & 0.000 & Positive relationship \\
\hline 2 & New relationship building & 0.000 & 0.419 & 2 & 0.303 & 0.000 & Positive relationship \\
\hline 3 & Self-presentation & 0.003 & 0.313 & 3 & 0.187 & 0.004 & Positive relationship \\
\hline 4 & Enjoyment & 0.001 & 0.294 & 4 & 0.206 & 0.002 & Positive relationship \\
\hline 5 & Perceived privacy risk & 0.217 & 0.222 & 5 & -0.101 & 0.125 & No Negative relationship \\
\hline
\end{tabular}

Regarding moderating effects of gender on five dimensions toward self-disclosure, tables 9 and10 indicate that, relative to self-disclosure, convenience of maintaining existing relationships, new relationship building, self-presentation, and enjoyment are significantly moderated by gender. The results reveal that men are motivated more by self-presentation and enjoyment when self-disclosing on SNSs than women are, and women are motivated more by maintaining existing relationships and building new relationships. Men perceived more risk that inhibits their self-disclosure on SNSs, and women not affected by perceived risk of disclosure of their personal information.

\subsection{Results and Discussion}

In this study, we investigated factors that motivate individuals to self-disclose on SNSs in the context of Saudi Arabia. Perceived benefits were found to be significantly and positively related to information disclosure behavior. To obtain benefits from SNS usage, such as convenience of maintaining relationships, building new relationships, and enjoyment, it is important for users to disclose personal information when interacting with other users. Note that this finding is supported in the literature (Cheung et al., 2015; Krasnova et al., 2010). Similar to the results reported by Cheung et al. (2015), our results indicate that self-presentation was positively related to self-disclosure.

The analysis demonstrated that convenience of maintaining relationships followed by building new relationships and enjoyment were the most influential benefits of self-disclosure on SNS in Saudi Arabia. Self-presentation was identified as the least influential benefit.

The technology that supports SNSs has enabled a wide range of online functions that make maintaining relationships easier than offline or face-to-face interactions. Such functions include the ability to share photographs, videos, messages, and thoughts. Social media sites also allow users to interact through status updates, wall updates, and private messages, thereby providing invaluable opportunities to maintain relationships.

In addition, the analysis results indicated that individuals believe that self-disclosure is necessary to meet new people and build new relationships. Therefore, to build networks and strengthen relationships on SNSs, individuals are willing to disclose more about themselves.

Furthermore, the study found that, relative to self-disclosure, enjoyment is an important factor. If individuals 
enjoy using an SNS, then they are more willing to self-disclose. Consequently, site designers should continue to incorporate "fun" features that motivate individuals to reveal more information.

Social media sites have multiple functionalities that allow an individual to influence the self-image they want to portray to others, and this is positively related to encouraging people to reveal more information. However, our results indicate that self-presentation is the least influential driver of self-disclosure on SNSs in Saudi Arabia. The reason for this may be that it is not necessary for Saudi participants to disclose a lot of information to project a certain image of themselves. Furthermore, given the current maturity of SNSs, close interdependence among friends may lead users to realize that exaggerated self-enhancement can be easily recognized by others (Krasnova, 2010).

We also found that gender plays an important role in motivation to self-disclose. The results reveal that, compared to women, men are motivated more by self-presentation and enjoyment. Women are motivated to self-disclose to maintain existing relationships and build new relationships. In addition, men consider privacy risks more than women do; thus, they tend to moderate the extent of self-disclosure. Women were less concerned about privacy risks and thus were more willing to disclose personal information.

However, despite the differences between men and women, overall there was a significant relationship between perceived privacy risks and self-disclosure. In other words, privacy risks have a significant negative impact on individual self-disclosure (i.e., individuals mitigate the amount of personal information they disclose based on perceived privacy threats). However, the analysis indicates that the impact of perceived privacy risk on self-disclosure is less than that of perceived benefit (the corresponding chi-square test yielded 0.233 for perceived privacy risk). This means that people are willing to disclose to gain perceived benefits, which encourages them to reveal more information regardless of the risk.

In addition, mitigating cost factors can reduce the perception of risk relative to information disclosure. This study found that perceived control, trust in the service provider, and trust in other members on SNSs mitigated risk concerns. Thus, when an SNS service provider is transparent about the information they collect and is perceived to be caring, honest, and consistent in dealing with users, users will be less sensitive to related privacy risks. Furthermore, the analysis also demonstrated that control features have a positive impact on trust in the service provider. The ability to set privacy controls encourages users to believe that they are in control of their privacy and can manage who accesses their information. The results also showed that the availability of control features that enable users to control access to personal information across their groups and the ability to report other users has a positive impact on trust in other SNS members.

\section{Conclusion and Implications}

Recognizing the importance of privacy and increasing concerns about privacy, this study has empirically identified factors involved in self-disclosure on SNSs in the Saudi context. We found that among the benefits of SNS platforms, convenience, relationship building, enjoyment, and self-presentation are significantly linked to information disclosure. Our findings demonstrate that SNS members engage in a privacy calculus process when determining what and how much personal information to disclose. From a practical perspective, our results provide important insights for SNS providers by identifying areas where providers should invest resources to ensure more communication and user activity that will help both business and public administration to understand people. We also contribute to ongoing research by demonstrating that, although risk hinders self-disclosure, it is often offset by benefits and mitigated by trust in the service provider, control mechanisms, and other users.

The current findings can benefit both practitioners and academics. For academics, the findings provide more up-to-date information about self-disclosure in the Saudi context. For practitioners, the results indicate that perceived benefits are the dominant predictors of self-disclosure on SNSs. Therefore, based on these results, SNS service providers should enrich their core functionalities by increasing the form and number of features and services. Such functionalities can promote the benefits identified in our analysis (i.e., convenience of maintaining relationships, building new relationships, enjoyment, and self-presentation). These perceived benefits can mitigate negative concerns about privacy risks because individuals have different preferences and value structures, and they may have different use purposes. Thus, features must be developed to provide specifically targeted benefits.

However, SNS providers must continue to be aware that perceived privacy risks prevent self-disclosure. Our study has revealed that three key mechanisms are involved in the mitigation of risk concerns (i.e., improving user control, increasing trust in SNS providers, and increasing trust in SNS members). Therefore, to enhance trust, SNSs providers must implement privacy policies that help to address privacy abuses. Providers should also prevent information collection by third parties. In addition, providers should enhance an individual user's sense 
of control over his or her personal information. Privacy management should be more transparent and user-friendly. Allowing users to manage access to their data will significantly reduce user perception of risk and increase their trust in both the service provider and the online community.

\section{Limitations and Future Work}

In this study, we focused primarily on individual self-disclosure using a privacy calculus theory. However, we recognize that constructs other than those investigated in our study may impact individual self-disclosure. We acknowledge that our specific focus may be a potential shortcoming of our approach. To broaden the contribution to the literature, future studies should consider other important constructs, such as social influence.

\section{References}

Abokhodair, N., \& Vieweg, S. (2016). Privacy \& social media in the context of the Arab Gulf. Proceedings of the 2016 ACM Conference on Designing Interactive Systems, 672-683. https://doi.org/10.1145/2901790.2901873

Ahmed, A. A. A. M. (2014). Self-presentation strategies among users of social networking sites. International Journal of Interactive Communication Systems and Technologies, 4, 64-78. https://doi.org/10.4018/IJICST.2014070105

Al-Saggaf, Y. (2016). An exploratory study of attitudes towards privacy in social media and the threat of blackmail: The views of a group of Saudi women. The Electronic Journal of Information Systems in Developing Countries, 75. https://doi.org/10.1002/j.1681-4835.2016.tb00549.x

Alarcón-Del-Amo, M. D. C., Lorenzo-Romero, C., \& Del Chiappa, G. (2014). Adoption of social networking sites by Italian. Information Systems and e-Business Management, 12, 165-187. https://doi.org/10.1007/s10257-013-0215-2

Altman, I., \& Taylor, D. A. (1973). Social penetration: The development of interpersonal relationships, New York, NY: Holt, Rinehart and Winston.

Barnes, S. B. (2006). A privacy paradox: Social networking in the United States. First Monday, 11.

Bateman, P. J., Pike, J. C., \& Butler, B. S. (2011). To disclose or not: Publicness in social networking sites. Information Technology \& People, 24, 78-100. https://doi.org/10.1108/09593841111109431

Bazarova, N. N., \& Choi, Y. H. (2014). Self-disclosure in social media: Extending the functional approach to disclosure motivations and characteristics on social network sites. Journal of Communication, 64, 635-657. https://doi.org/10.1111/jcom.12106

Benson, V., Saridakis, G., \& Tennakoon, H. (2015). Information disclosure of social media users: Does control over personal information, user awareness and security notices matter? Information Technology \& People, 28, 426-441. http:dx.doi.org/10.1108/ITP-10-2014-0232

Carr, C. T., \& Hayes, R. A. (2015). Social media: Defining, developing, and divining. Atlantic Journal of Communication, 23, 46-65. https://doi.org/10.1080/15456870.2015.972282

Chen, X., Pan, Y., \& Guo, B. 2016. The influence of personality traits and social networks on the self-disclosure behavior of social network site users. Internet Research, 26, 566-586. https://doi.org/10.1108/IntR-05-2014-0145

Cheung, C., Lee, Z. W. Y., \& Chan, T. K. H. (2015). Self-disclosure in social networking sites: The role of perceived cost, perceived benefits and social influence. Internet Research, 25, 279-299. https://doi.org/10.1108/IntR-09-2013-0192

Chiu, C. M., Hsu, M. H., \& Wang, E. T. (2006). Understanding knowledge sharing in virtual communities: An integration of social capital and social cognitive theories. Decision Support Systems, 42, 1872-1888.

Chou, Y.-J., Teng, C.-I., \& Lo, S. -K. (2009). Mutual self-disclosure online in the B2C context. Internet Research, 19, 466-478. DOI: 10.1108/10662240910998878Cozby, P. C. (1973). Self-disclosure: A literature review. Psychological Bulletin, 79, 73. https://doi.org/10.1037/h0033950

Culnan, M. J., \& Armstrong, P. K. (1999). Information privacy concerns, procedural fairness, and impersonal trust: An empirical investigation. Organization Science, 10, 104-115. https://doi.org/10.1287/orsc.10.1.104

Derlega, V. J., Durham, B., Gockel, B., \& Sholis, D. (1981). Sex differences in self-disclosure: Effects of topic content, friendship, and partner's sex. Sex Roles, 7, 433-447. https://doi.org/10.1007/BF00288071 
Derlega, V. J., Metts, S., Petronio, S., \& Margulis, S. T. (1993). Self-disclosure, Newbury Park. CA: Sage. https://doi.org/10.1002/9781118540190.wbeic0162

Dienlin, T., \& Metzger, M. J. (2016). An extended privacy calculus model for SNSs: Analyzing self-disclosure and self-withdrawal in a representative U.S. sample. Journal of Computer-Mediated Communication, 21, 368-383. https://doi.org/10.1111/jcc4.12163

Dimitrios, X., \& Violettas, G. (2014). Examining the level of trust of Saudis towards the social media. Information Science and Technology (ICIST), 2014 4th IEEE International Conference on IEEE (pp. 586-589).

Dindia, K., \& Allen, M. (1992). Sex differences in self-disclosure: A meta-analysis. Psychological Bulletin, 112, 106.

Dinev, T., \& Hart, P. (2006). An extended privacy calculus model for e-commerce transactions. Information Systems Research, 17, 61-80. https://doi.org/10.1287/isre.1060.0080

Ellison, N. B. (2007). Social network sites: Definition, history, and scholarship. Journal of Computer-Mediated Communication, 13, 210-230. https://doi.org/10.1111/j.1083-6101.2007.00393.x

Globalwebindex. (2017). Q2. GlobalWebIndex report on the latest trends in social media - GWI Social.

Guta, H., \& Karolak, M. (2015). Veiling and blogging: social media as sites of identity negotiation and expression among Saudi women. Journal of International Women's Studies, 16(2), 115-127.

Hajli, N. \& Lin, X. 2016. Exploring the security of information sharing on social networking sites: The role of perceived control of information. Journal of Business Ethics, 133, 111-123.

Haynes, D., \& Robinson, L. (2015). Defining user risk in social networking services. Aslib Journal of Information Management, 67, 94-115. https://doi.org/10.1108/AJIM-07-2014-0087

Hollenbaugh, E. E., \& Ferris, A. L. (2014). Facebook self-disclosure: Examining the role of traits, social cohesion, and motives. Computers in Human Behavior, 30, 50-58. https://doi.org/10.1016/j.chb.2013.07.055

Huang, H. Y. (2016). Examining the beneficial effects of individual's self-disclosure on the social network site. Computers in Human Behavior, 57, 122-132. https://doi.org/10.1016/j.chb.2015.12.030

Hui, K. L., Tan, B. C., \& Goh, C. Y. (2006). Online information disclosure: Motivators and measurements. $A C M$ Transactions on Internet Technology, 6, 415-441.

Jarvenpaa, S. L., Tractinsky, N., \& Saarinen, L. (1999). Consumer trust in an Internet store: A cross-cultural validation. Journal of Computer-Mediated Communication, 5.

Jourard, S. M. (1964). The transparent self: Self-disclosure and well-being. New York ,United States: Van Nostrand.

Jourard, S. M. (1971). Self Disclosure: An Experimental Analysis of the Transparent Self. New York, Wiley-Interscience.

Kang, Y., Park, J., \& Liu, J. (2012). A study on the online shopper's self-disclosure. Academy of Marketing Studies Journal, 16, 19.

Kim, D. J., Ferrin, D. L., \& Rao, H. R. (2008). A trust-based consumer decision-making model in electronic commerce: The role of trust, perceived risk, and their antecedents. Decision Support Systems, 44, 544-564. https://doi.org/10.1016/j.dss.2007.07.001

Kokolakis, S. (2017). Privacy attitudes and privacy behaviour: A review of current research on the privacy paradox phenomenon. Computers \& Security, 64, 122-134. https://doi.org/10.1016/j.cose.2015.07.002

Krasnova, H., Spiekermann, S., Koroleva, K., \& Hildebrand, T. (2010). Online social networks: Why we disclose. Journal of Information Technology, 25, 109-125.

Krasnova, H., Veltri, N. F., \& Günther, O. (2012). Self-disclosure and privacy calculus on social networking sites: The role of culture: Intercultural dynamics of privacy calculus. Business \& Information Systems Engineering, 4, 127-135. https://doi.org/10.1007/s12599-012-0216-6 
Lee, H., Park, H., \& Kim, J. (2013). Why do people share their context information on social network services? A qualitative study and an experimental study on users' behavior of balancing perceived benefit and risk. International Journal of Human-Computer Studies, 71, 862.

Li-Barber, K. T. (2012). Self-disclosure and student satisfaction with Facebook. Computers in Human Behavior, 28, 624-630. https://doi.org/10.1016/j.chb.2011.11.008

Liang, H., Shen, F., \& Fu, K. W. (2016). Privacy protection and self-disclosure across societies: A study of global twitter users. New Media \& Society, https://doi.org/10.1177/1461444816642210

Loiacono, E. T. (2015). Self-disclosure behavior on social networking web sites. International Journal of Electronic Commerce, 19, 66.

Malhotra, N. K., Kim, S. S., \& Agarwal, J. (2004). Internet users' information privacy concerns (IUIPC): The construct, the scale, and a causal model. Information Systems Research, 15, 336-355. https://doi.org/10.1287/isre. 1040.0032

Malik, A., Hiekkanen, K., \& Nieminen, M. (2016). Privacy and trust in Facebook photo sharing: Age and gender differences. Program, 50, 462-480. https://doi.org/10.1108/PROG-02-2016-0012

McKnight, D. H., Choudhury, V., \& Kacmar, C. (2002). Developing and validating trust measures for e-commerce: An integrative typology. Information Systems Research, 13, 334-359.

Min, J., \& Kim, B. (2015). How are people enticed to disclose personal information despite privacy concerns in social network sites? The calculus between benefit and cost. Journal of the Association for Information Science and Technology, 66, 839-857. https://doi.org/10.1002/asi.23206

Nambisan, S., \& Baron, R. A. (2007). Interactions in virtual customer environments: Implications for product support and customer relationship management. Journal of Interactive Marketing, 21, 42-62. https://doi.org/10.1002/dir.20077

Nemec Zlatolas, L., Welzer, T., Heričko, M., \& Hölbl, M. (2015). Privacy antecedents for SNS self-disclosure: The case of Facebook. Computers in Human Behavior, 45, 158-167. https://doi.org/10.1016/j.chb.2014.12.012

O’Brien, D., \& Torres, A. M. (2012). Social networking and online privacy: Facebook users' perceptions. Irish Journal of Management, 31, 63.

Paliszkiewicz, J., \& Madra-Sawicka, M. (2016). The self-presentation in social media in example of Linkedin. Managing innovation and diversity in knowledge society through turbulent time: Proceedings of the MakeLearn and TIIM Joint International Conference 2016.

Salehan, M., Kim, D. J., \& Koo, C. (2016). A study of the effect of social trust, trust in social networking services, and sharing attitude, on two dimensions of personal information sharing behavior. The Journal of Supercomputing.

Sheldon, P. (2013). Examining gender differences in self-disclosure on Facebook versus face-to-face. The Journal of Social Media in Society, 2.

Skinner, E. A. (1996). A guide to constructs of control. Journal of Personality And Social Psychology, 71, 549.

Stern, T., \& Salb, D. (2015). Examining online social network use and its effect on the use of privacy settings and profile disclosure. Bulletin of Science, Technology \& Society, 35, 25-34. https://doi.org/10.1177/0270467615596890

Syn, S. Y., \& Oh, S. (2015). Why do social network site users share information on Facebook and Twitter? Journal of Information Science, 41, 553-569. https://doi.org/10.1177/0165551515585717

Taddicken, M. (2014). The 'privacy paradox' in the social web: The impact of privacy concerns, individual characteristics, and the perceived social relevance on different forms of self-disclosure. Journal of Computer-Mediated Communication, 19, 248-273. https://doi.org/10.1111/jcc4.12052

Tifferet, S., \& Vilnai-Yavetz, I. (2014). Gender differences in Facebook self-presentation: An international randomized study. Computers in Human Behavior, 35, 388-399. https://doi.org/10.1016/j.chb.2014.03.016

Trepte, S., Reinecke, L., Ellison, N. B., Quiring, O., Yao, M. Z., \& Ziegele, M. (2017). A cross-cultural perspective on the privacy calculus. Social Media + Society, 3. https://doi.org/10.1177/2056305116688035

Varnali, K., \& Toker, A. (2015). Self-disclosure on social networking sites. Social Behavior and Personality: An International Journal, 43, 1-13. https://doi.org/10.2224/sbp.2015.43.1.1 
Walther, J. B., Slovacek, C. L., \& Tidwell, L. C. (2001). Is a picture worth a thousand words? Photographic images in long-term and short-term computer-mediated communication. Communication Research, 28, 105-134. https://doi.org/10.1177/009365001028001004

Walton, S. C., \& Rice, R. E. (2013). Mediated disclosure on Twitter: The roles of gender and identity in boundary impermeability, valence, disclosure, and stage. Computers in Human Behavior, 29, 1465-1474. https://doi.org/10.1016/j.chb.2013.01.033

Wang, Y. C., Burke, M., \& Kraut, R. (2016). Modeling self-disclosure in social networking sites. Proceedings of the 19th ACM Conference on Computer-Supported Cooperative Work \& Social Computing (pp. 74-85). https://doi.org/10.1145/2818048.2820010

Zhang, L., Amos, C., \& Pentina, I. (2015). Information disclosure on a Chinese social media platform. Journal of Information Privacy and Security, 11, 3-18. https://doi.org/10.1080/15536548.2015.1010981

\section{Copyrights}

Copyright for this article is retained by the author(s), with first publication rights granted to the journal.

This is an open-access article distributed under the terms and conditions of the Creative Commons Attribution license (http://creativecommons.org/licenses/by/4.0/). 